\title{
La explotación de los corpus, bases de datos y diccionarios en el Refranero bilingüe español-croata: estudio de caso
}

\author{
Exploitation of corpora, databases and dictionaries in the \\ Refranero bilingüe español-croata: a case study
}

\author{
Ivana Lončar \\ Universidad de Zadar, Croacia
}

\begin{abstract}
Resumen: El objetivo del presente trabajo es demostrar y cuestionar la explotación de los corpus, bases de datos y diccionarios en la elaboración de un diccionario bilingüe de refranes españolcroata comprendiendo por una parte las consabidas incongruencias entre la pragmática y la lexicografía (¿̇se utiliza de verdad lo que está en el diccionario? en el caso de variantes, ¿̇cuál es el lema "canónico"?, ¿̇son sinónimos los refranes de significado parecido?), y por otra, considerando los principios de paremiografía contrastiva (equivalentes paremiológicos y tipos de equivalencia, falsos amigos paremiológicos).
\end{abstract}

Palabras clave: corpus, croata, español, paremiografía bilingüe, refranes.

Abstract: The aim of this paper is to demonstrate and question the exploitation of corpus, databases and dictionaries in the production of a bilingual dictionary of Spanish-Croatian proverbs, discussing on the one hand the well-known incongruities between pragmatics and lexicography (Do we actually use what is in the dictionary? In the case of variants, what is the canonical entry? Can we consider the proverbs with similar meaning as synonyms?), and on the other, considering the principles of contrastive paremiography (paremiological equivalents, types of equivalence, paremiological false friends).

Keywords: corpus, Croatian, Spanish, bilingual paremiography, proverbs.

\section{Introducción}

En el campo de la paremiología últimamente destacan trabajos publicados sobre la enseñanza de unidades fraseológicas, entre ellas, las paremias en clase de español como lengua extranjera (Penadés Martínez, 1999, 2008, 2015; Sardelli, 2012; Barani, 2013; Sevilla Muñoz, 2005b; Tarnovska 2005; Gómez González, 2015, entre otros). Asimismo, el proyecto de elaboración de un diccionario bilingüe de refranes español-croata (más adelante, Refranero Bilingüe) se ha iniciado con el fin de ampliar las escasas herramientas didácticas de las que disponen los estudiantes de español en Croacia. Habida cuenta de que algunos de ellos se especializan en estudios de traducción, entre ellos, traducción literaria, destaca la necesidad de desarrollar un buen dominio de la lengua y unas altas competencias lingüísticas, entre ellas, la competencia fraseológica y paremiológica. 
El ámbito de las paremias, cuyo núcleo lo componen los refranes, siempre suscita recelos por el poco rigor con que se tratan, sobre todo si pensamos en los infinitos listados de "dichos y frases hechas» españoles y sus supuestos equivalentes en varias lenguas del mundo disponibles en Internet. Partiendo de las bases teóricas consideradas en la elaboración de una macroestructura metodológicamente fundada y el diseño de una microestructura cuyos datos se corresponderían con las necesidades de los destinatarios, se ha esbozado un artículo lexicográfico que, entre otra información, incluye ejemplos de uso, la contextualización, de los refranes en ambas lenguas (español como lengua de partida y croata como lengua de destino). El Refranero Bilingüe se está elaborando a través de la explotación de las tres herramientas citadas en el título: diccionarios y refraneros (monolingües, bilingües y multilingües), bases de datos (en su mayoría, refraneros), así como varios corpus de ambas lenguas.

La presente investigación comprende por una parte las consabidas incongruencias entre la pragmática y la lexicografía ( $\dot{s}$ se utiliza de verdad lo que está en el diccionario?, en el caso de variantes, ¿̇cuál es el lema "canónico"? ¿̇son sinónimos los refranes de significado parecido?), y, por otra, considera los principios de paremiografía contrastiva (correspondencias 0 equivalentes paremiológicos, tipos y grados de equivalencia, falsos amigos paremiológicos). Finalmente, también trata algunas cuestiones meramente prácticas: manejo y explotación de los corpus, búsqueda de ejemplos representativos de uso auténtico de un refrán (tratándose de unidades fraseológicas sintácticamente autónomas "susceptibles de funcionar como enunciados con carácter de texto" (Corpas Pastor, 1996: 136), el tratamiento de los refranes que se repiten de un diccionario a otro, sin que aparezcan en los corpus, entre otros recursos similares, y sin que sus usos reales se puedan encontrar ni siquiera en un espacio tan inmenso como es la red, etc.

\section{Refranero bilingüe español-croata}

Para determinar la macroestructura del Refranero Bilingüe se ha partido de dos criterios principales. El primero de ellos consiste en la necesidad de elaborar una herramienta lexicográfica eficiente para los traductores (teniendo en cuenta que la lexicografía croata no dispone de un diccionario croataespañol y que el único diccionario bilingüe español-croata (Vinja, 2005), a pesar de numerosas reediciones, requiere serias enmiendas y ampliaciones), mientras que el segundo se basa en la competencia léxica (más concretamente, paremiológica) de estudiantes de español en formación para ser traductores.

Por lo tanto, ante la pregunta de investigación ¿̇qué refranes formarán "el lado izquierdo del diccionario?" (fórmula habitual para referirse al conjunto de lemas, es decir, a la macroestructura, en la lexicografía croata) se han seguido las siguientes pautas: la macroestructura del Refranero Bilingüe comprenderá todos los refranes que a) forman parte del "mínimo paremiológico español" (Tarnovska, 2005); b) en el Refranero Multilingüe (Sevilla Muñoz \& Zurdo RuizAyúcar, 2009; Sevilla Muñoz 2001)' están marcados con el marcador de uso "de uso actual" o "muy usado", con tal de que lo confirmen sus ocurrencias en

\footnotetext{
$1<\mathrm{http}: / /$ cvc.cervantes.es/lengua/refranero/> [febrero 2016]
} 
los corpus y c) todos los refranes españoles registrados a lo largo de la investigación que presenten el mismo marcador de uso. Cabe destacar, tal y como advierten Ruiz Zorrilla-Cruzate et al.,
[...] se constata la necesidad de un marco teórico que permita el uso de un instrumento de tan alto valor para el lingüista, fraseólogo y/o paremiólogo, como es Internet (Ruiz Zorrilla-Cruzate et al., 2012, 43).

La microestructura del Refranero Bilingüe (denominada en la lexicografía croata como "el lado derecho del diccionario") consta de varios elementos que a continuación se especifican:

1. Lema: Comprende los refranes que cumplen con los requisitos establecidos para la macroestructura. Como forma "canónica", es decir, el lema, se ha tomado aquel refrán que, según las ocurrencias en los corpus, ha presentado más frecuencia de uso. En caso de los refranes bimembres, el signo de puntuación optativo (la coma) se indica entre corchetes, siguiendo el modelo del ParemioRom (Gargallo Gil, 2011).

2. Traducción literal: Debajo del lema, entre corchetes, precedida por un asterisco, se proporciona la traducción literal del lema a la lengua croata. Huelga decir que la experiencia docente en la enseñanza de español como lengua extranjera ha demostrado que la traducción literal de las unidades fraseológicas facilita su memorización y, a su vez, refuerza la competencia léxica de los estudiantes. Asimismo, consideramos que la traducción literal de fraseologismos y paremias ofrece datos valiosos para las investigaciones de lingüística contrastiva.

3. Variantes: Se enumeran, si procede, las variantes del lema, indicando la fuente lexicográfica en la que se han registrado. Las variantes registradas en Internet se marcan con [G]. Siguiendo el modelo propuesto por Penadés Martínez (2008), se prescinde de las variaciones ortográficas y se proporcionan variantes documentadas correspondientes a cambios morfológicos, sintácticos y léxicos.

4. Acepciones: Se proporcionan todas las acepciones del lema que se han podido documentar en los corpus, cada una precedida por el número correspondiente, que más adelante se repetirá tras el correspondiente refrán croata.

5. Información pragmática: Casos en los que se ha considerado oportuno señalar alguna pauta de uso especial.

6. Ejemplos de uso del refrán español: Se aportan contextos en los que aparecen las acepciones del lema confirmados en los corpus o en la red. Este apartado del artículo lexicográfico se tratará con más detalle a lo largo del presente trabajo.

7. Refrán correspondiente croata: Se han dado casos de "poliequivalencia" (Mellado Blanco, 2015), en los que varias acepciones del mismo refrán español se corresponden a varios refranes o expresiones croatas. Dichos equivalentes paremiológicos se indican precedidos por el número de la acepción del lema.

8. Tipo de equivalencia: Para el Refranero Bilingüe se han establecido varios tipos de equivalencia entre los refranes de la lengua de partida y los de la lengua meta, que se proporcionan en este apartado (Sevilla Muñoz, 2004; Mellado Blanco, 2015). 
9. Variantes del refrán croata: Se sigue la misma metodología indicada para las variantes del lema.

10. Ejemplos de uso del refrán o refranes correspondientes: Se siguen, en la medida de lo posible, los criterios establecidos por Mellado Blanco (2015) de equivalencia lexicográfica de los refranes.

[...] La equivalencia lexicográfica debe obtenerse mediante el análisis del comportamiento prototípico de las unidades fraseológicas en el nivel del discurso, para lo cual es esencial saber discriminar los usos típicos de los periféricos o poco representativos. [...], la equivalencia lexicográfica se diferencia de la equivalencia textual en que no pretende hacerse eco de toda la casuística posible de traducciones de un fraseologismo de la L1 en L2. Además de ello, en los diccionarios sería aconsejable que junto a las equivalencias en la L2 se explicaran las posibles restricciones de Uso, cuestiones combinatorias o divergencias en la estructura del significado de los respectivos fraseologismos en la L2. (Mellado Blanco, 2015: 155)

\section{Explotación de los diccionarios y bases de datos}

Tal y como proviene de su definición lexicográfica, más que un diccionario, un refranero es una colección de refranes (cfr. DRAE). A pesar del exuberante caudal de refraneros de los que dispone la paremiografía española, de los que los más antiguos datan de la Edad Media (Sevilla Muñoz, 1996: 641) no se trata de diccionarios, sino, en la mayoría de los casos y con escasas excepciones (Cantera \& Sevilla, 1998; Muñoz \& Cantera, 2001; Carbonell Basset; 2002, entre otros), de recopilaciones de los refranes. Si tenemos en cuenta que a las investigaciones de los aspectos lingüísticos de los refranes les precede el laborioso trabajo de etnógrafos, folcloristas y otros estudiosos del acervo folclórico de los pueblos, podemos deducir que para un trabajo lexicográfico tendremos que recurrir a los diccionarios de refranes más recientes, elaborados en el seno de lexicografía moderna. Igualmente, en la paremiografía de la lengua meta (Botica, 2007; Kekez, 1984, 1990, 1996; Mikić \& Škara, 1992; Skarpa, 2004) no se ha registrado ni un solo refranero que, además del lema, y en algunos casos sus variantes, ofrezca datos que se correspondan con la microestructura de un diccionario. El único diccionario bilingüe español-croata (Vinja, 2005) aporta aleatoriamente algún que otro refrán y su correspondencia croata, tratándose en la mayoría de los casos de los refranes del Quijote.

Por lo tanto, a la hora de elaborar la microestructura se ha recurrido principalmente al diccionario 70 refranes para la enseñanza del español (Penadés Martínez et al., 2008), de carácter didáctico y destinado a los estudiantes de español como lengua extranjera. Dado que se trata de un diccionario multilingüe, con correspondencias paremiológicas en inglés, chino y portugués de Brasil, el modelo de Penadés Martínez nos ha servido en la modelación del artículo lexicográfico, que en nuestro proyecto se ha ampliado con la descripción lexicográfica de los refranes de la lengua de destino, datos que no posee este diccionario. Asimismo, en la elaboración de la microestructura nos hemos servido de las descripciones lexicográficas del Refranero Multilingüe (Sevilla Muñoz et al., 2009) disponible en línea, que en varios aspectos sobrepasa la acepción del término refranero. Se trata, más 
que de un refranero o diccionario de refranes, de una base de datos multilingüe, elaborada como una plataforma electrónica, que, además de proporcionar variantes, sinónimos y contextos (ejemplos de uso), facilita la búsqueda por varios parámetros (lema, idioma, idea clave).

Ambos proyectos paremiográficos presentan una ficha lexicográfica que ha podido servir como punto de partida para la microestructura del presente proyecto, según los criterios establecidos, especialmente a lo que se refiere a los citados ejemplos de uso.

El diseño de la microestructura (citado arriba) se ha elaborado teniendo siempre en cuenta las necesidades del usuario, a través de varios modelos de prueba ampliados, enmendados y perfeccionados mediante las encuestas. En este sentido, la información lexicográfica disponible en el diccionario 70 refranes y la plataforma Refranero Multilingüe han aportado valiosos datos para la macroestructura y partes de la microestructura de nuestro proyecto, como son los parámetros de variantes, sinónimos, y las acepciones de los refranes de la lengua de partida.

\section{Explotación de los corpus}

En la presente investigación se han explotado tres corpus de la lengua de partida (CORDE, CREA y CORPES) y dos de la lengua meta (HNK, hrWaC). La parte del artículo lexicográfico en la que predominan los corpus como herramienta principal de la investigación es la dedicada a los ejemplos de uso, es decir, contextos en los que aparecen los refranes. Para demostrar los principales problemas de investigación y trabajo paremiográfico, intentaremos ejemplificarlos mediante unos refranes españoles que forman parte de la macroestructura del Refranero Bilingüe.

El refrán A Dios rogando y con el mazo dando, según las fuentes lexicográficas y las ocurrencias en los corpus, resulta polisémico, es decir, tiene varias acepciones. La primera, registrada en varios diccionarios, se especifica en el 70 refranes: "Para conseguir alguna cosa, no es suficiente pedírsela a Dios, sino que es necesario el propio esfuerzo" (Penadés Martínez et al. 2008, pág.), mientras que en la segunda, según el Refranero Multilingüe, se critica la hipocresía de algunos creyentes. Ambos usos están confirmados en los corpus, y las acepciones del refrán español se presentan por dos refranes distintos de la lengua destino: 1. Pomozi si sam pa će ti i Bog pomoći [*Ayúdate a ti mismo y Dios te ayudará] y 2. Boga moli, a vragu se klanja [*Rezando a Dios y prosternándose a Diablo]. Sin embargo, el Refranero Multilingüe como sinónimo de este refrán ofrece A quien madruga[,] Dios le ayuda, acepción que no hemos podido comprobar ni en los corpus del español ni en buscadores de Internet, por lo que se ha descartado la sinonimia de estos dos refranes.

El principal problema de los corpus, especialmente de la lengua de partida, consiste en que como herramienta de explotación para las investigaciones lingüísticas no siempre son adecuados para las pesquisas de la lingüística contrastiva, especialmente si se trata del campo del español como lengua extranjera. Tratándose de los corpus diacrónicos (CORDE) y corpus de referencia del español, es difícil encontrar ejemplos sencillos y adecuados al alumnado. Los mismos problemas se presentan en la búsqueda de ejemplos 
de uso de unidades léxicas pensadas para ciertos niveles de dominio de la lengua, especialmente si el fenómeno investigado se corresponde a la adquisición de los niveles bajos (A1-A2). Así por ejemplo, para el archiconocido refrán No es oro todo lo que reluce, que aparece en El mercader de Venecia de Shakespeare, traducido a muchas lenguas y parte del saber común de la cultura occidental, el principal problema ha sido encontrar un ejemplo de uso suficientemente sencillo y clarificador, y por lo tanto útil para los usuarios. Al final, tras varias consultas y encuestas, los estudiantes optaron por un ejemplo procedente del buscador Google: "No es oro todo lo que reluce, las abdominales y pectorales de Justin Bieber llevan Photoshop". [G]

El refrán meteorológico Por Santa Catalina[,] la nieve se avecina, que alude al tiempo meteorológico a finales de noviembre, ya que el día de la santa se celebra el 25 de ese mes, tiene su equivalente en varios idiomas, entre ellos el refrán croata, con rima: Sveta Kata, snijeg za vrata [ ${ }^{*} S a n t a$ Catalina, la nieve en la puerta]. No obstante, en un espacio tan inmenso como es la red, son poquísimos los ejemplos de uso de este refrán, no registrado en los corpus: "¡Ya estamos en el tercer fin de semana de noviembre! Muy pronto será Santa Catalina, y como dice el refranero español, por Santa Catalina la nieve y el frío se avecinan." [G] Lo mismo ocurre en la lengua de destino, donde el refrán suele aparecer como título de prensa que acompaña la noticia de la primera nieve del invierno. Probablemente por esta razón, los diccionarios de refranes, a la hora de indicar ejemplos de uso, igual que, por ejemplo, las gramáticas de español como lengua extranjera para los niveles más bajos, en vez de proporcionar ejemplos del corpus, recurren a contextos recreados, método que en el presente proyecto se ha intentado evitar.

Asimismo, a lo largo de la investigación, sobre todo a la hora de confirmar todas las posibles acepciones de un refrán, han aparecido extensiones de los significados no registrados en las fuentes lexicográficas de la lengua de destino, aunque de uso frecuente, o en los corpus o en los textos en la red. Así, el antiguo refrán gongorino Ande yo caliente y ríase la gente, además de utilizarse

[...] cuando uno prefiere su gusto o comodidad a someterse a la opinión de los demás o a los convencionalismos sociales. También se emplea para recomendar actuar rectamente y de acuerdo con la propia conciencia, sin tener en cuenta la opinión de los demás. (Refranero Multilingüe)

y de aparecer en las obras antiguas (cfr. los contextos proporcionados por el Refranero Multilingüe, de 1646 y de 1842), en los textos recientes parece ser que resucita con el significado de "en tiempos fríos, es más importante abrigarse bien que someterse a criterios estéticos", tal y como proviene de los siguientes ejemplos:

Ya podéis dejar de reíros al ver lo que os propongo contra el frío helado que estamos sufriendo: los calzoncillos largos. Son los que los usan -y los hay, no tengáis ninguna duda - que se ríen de vosotros, los que pasáis frío. [G]

Este fin de semana las botas de agua han dejado de ser una opción para convertirse en una necesidad en muchos puntos de España. "Ande yo caliente y ríase la gente" eso es lo que hemos pensado 
muchos al incorporarlas a nuestro estilismos, fuera cual fuera este. Un hecho que me ha hecho preguntarme, ¿̇de qué forma acostumbramos a combinar las botas de agua? Las siguientes imágenes nos aportan algunas respuestas, aunque no todas. Con vaqueros y capas, vestidos y abrigos de paño... las propuestas son numerosas y variadas para adaptarse a diferentes circunstancias, ¿̇uál es la tuya? [G]

Curiosamente, el registro de la lengua de partida que abunda en refranes parece ser el lenguaje periodístico y los textos que tratan la vida política del país. El no tratarse de política internacional, sino de los hechos políticos poco conocidos fuera de España, es una de las razones por las que las contextualizaciones no resultan clarificadoras para los hablantes no nativos del español. Veamos los siguientes ejemplos:

La presidenta de la Comunidad de Madrid, Esperanza Aguirre, ha rectificado esta mañana las duras palabras que les dirigió a los docentes la semana pasada al asegurar que solo trabajaban 20 horas a la semana y que la mayoría de los madrileños trabaja más que ellos. Aguirre ha asegurado que sabe perfectamente las horas que trabajan los docentes y ha reconocido que sus palabras fueron "poco afortunadas". "El que tiene boca se equivoca", ha apostillado. [El País, 7/09/2011]

Al buen entendedor, pocas palabras bastan, debió pensar Camps, cuando comentó que "nos duele" que el presidente Rodríguez Zapatero no haya dicho "qué va a hacer con las reformas territoriales", ya que considera que es "grave" que no se sepa todavía, pero aún lo es más que "está jugando con algo tan importante como es España". [CORPES]

Es deber de los diputados escuchar de sus electores, los ciudadanos, a quienes representan, para atender sus puntos de vista y evaluar si las leyes no limitan o coartan sus derechos. Desde luego, se reconoce que "una golondrina no hace verano"; pero es innegable que este libre intercambio de ideas es el que genera un campo propicio para promulgar leyes con un contenido inteligente, claro, beneficioso y con una amplia base de apoyo público. [CREA]

Olga María Henao, conocida por ser la ex novia canaria de José Antonio Monago, encendió las redes sociales este domingo por la noche al publicar en su cuenta personal de Twitter que "a todo cerdo le llega su San Martín". Puestos en contacto con esta empresaria colombiana afincada en Tenerife que saltó a la palestra informativa después de que se destaparan los viajes del presidente de Extremadura a cargo del Senado a la isla, ha manifestado que no se refería a él. [El Mundo, 25/05/15]

Por todas las razones arriba indicadas, consideramos que el parámetro del artículo lexicográfico referido a los ejemplos de uso de los refranes españoles es donde más resalta la necesidad de una explotación rigurosa y metodológicamente fundada de la presente investigación lingüística.

\section{A modo de conclusión}

Los tres instrumentos citados en el título del presente trabajo, los diccionarios, las bases de datos, así como los corpus, se presentan como herramientas 
admirables e imprescindibles en toda investigación lingüística. Cada uno de ellos, a su modo, proporciona información indispensable, especialmente en el campo de la lingüística contrastiva enfocado en la enseñanza del español como lengua extranjera. A la hora de explotarlos, no obstante, resulta fundamental seguir los criterios de la investigación, así como valorar con un enfoque crítico su utilidad teniendo en cuenta los objetivos de la investigación. Tratándose de un proyecto lexicográfico bilingüe, los diccionarios y los refraneros han servido como punto de partida de la investigación, mientras que los corpus se han empleado tanto para confirmar ocurrencias de los refranes en la lengua de partida, como para la elaboración del artículo lexicográfico bilingüe. Como ya se ha aclarado a lo largo del presente trabajo, a la hora de explotar los corpus de referencia de la lengua de partida resulta complejo barajar la muestra más adecuada, entendible y suficientemente clara para el alumnado del español como lengua extranjera. En este sentido, el investigador puede recrear contextos de uso o recurrir a los innumerables textos de Internet en búsqueda del resultado idóneo. En este caso, tal y como advierten algunos autores, también es necesario seguir una metodología rigurosa, para no caer en trampa de deducir hechos que, por defectos que tiene la red, aparentan situaciones de uso no reales, especialmente en cuanto a las ocurrencias, frecuencia de uso, etc. Por ello, con este proyecto pretendemos fomentar la reflexión sobre la equivalencia paremiológica y solventar las dificultades que puede encontrar un investigador, traductor 0 estudiante a la hora de explotar las tres herramientas inevitables en toda investigación lingüística.

\section{Bibliografía}

\section{Corpus}

AGIC, Ž. \& LJUBESIC, N. hrWaC - Croatian Web Corpus. - hrWac

<http://nlp.ffzg.hr/resources/corpora/hrwac/> [febrero 2016]

REAL ACADEMIA ESPAÑOLA. Corpes XXI - Corpus del Español del siglo XXI.

$<$ http://web.frl.es/CORPES/view/inicioExterno.view> [febrero 2016]

REAL ACADEMIA ESPAÑOLA: Banco de datos (CORDE) [en línea]. Corpus diacrónico del español. <http://www.rae.es> [febrero 2016]

REAL ACADEMIA ESPAÑOLA: Banco de datos (CREA) [en línea]. Corpus de referencia del español actual. <http://www.rae.es> [febrero 2016]

TADIĆ M. et al, Hrvatski nacionalni korpus - HNK. <http://www.hnk.ffzg.hr/> [febrero 2016]

\section{Diccionarios y refraneros}

BOTICA, S. (2007): Kad ti kuća gori, a ti se ogrij. Zbirka poslovica Bartula Matijace. Zagreb: Naklada Pavičić.

CARBONELL BASSET, D. (2002): Diccionario panhispánico de refranes (De autoridades e ideológico). Barcelona: Herder.

KEKEZ, J. (1984): Poslovice i njima srodni oblici. Zagreb: Zavod za znanost o književnosti.

KEKEZ, J. (1996): Poslovice, zagonetke i govornički oblici. Zagreb: Matica hrvatska. 
KEKEZ, J. (1990): Svaki je kamen da se kuća gradi. Osijek: Izdavački centar „Revija" Otvorenoga sveučilišta, Osijek.

MIKIĆ, P. \& D. ŠKARA (1992): Kontrastivni rječnik poslovica. Zagreb: August Cesarec, Školska knjiga.

PENADÉS MARTÍNEZ, M. I., R. PENADÉS MARTÍNEZ, H. XIAOJING \& M. A. OLIMPIO DE OLIVEIRA SILVA (2008): 70 refranes para la enseñanza del español. Alcalá de Henares: Servicio de publicaciones.

REAL ACADEMIA ESPAÑOLA. (2001): Diccionario de la lengua española, $22^{a}$ ed., disponible en <www.rae.es> [marzo 2016]

SEVILLA MUÑOZ, J. \& CANTERA ORTIZ DE URBINA, J. (eds.) (1998-2000): 877 refranes españoles con su correspondencia catalana, gallega, vasca, francesa e inglesa. Madrid: Ediciones Internacionales Universitarias.

- (eds.) (2001): 1001 refranes españoles con su correspondencia en ocho lenguas (alemán, árabe, francés, inglés, italiano, polaco, provenzal y ruso). Madrid: Eiunsa.

SKARPA, V. J. (2004): Hrvatske narodne poslovice. Zagreb: Genesis.

VINJA, V. (2005): Španjolsko-hrvatski rječnik. Zagreb: Školska knjiga.

\section{Bases de datos}

GARGALLO GIL, J. E. (coord.): (2011-): ParemioRom. Paremiología romance: refranes meteorológicos y territorio. Disponible en < http://stel.ub.edu/paremio-rom/es> [febrero 2016]

SEVILLA MUÑOZ, J. \& M. I. T. ZURDO RUIZ-AYÚCAR (dir.) (2009): Refranero multilingüe. Madrid. Instituto Cervantes (Centro Virtual Cervantes). Disponible en <http://cvc.cervantes.es/lengua/refranero/> [febrero 2016]

\section{Referencias bibliográficas}

BARANI, N. (2013): Aspectos de la utilización de paremias en el diario El País [ebook]. Salamanca: Ediciones Universidad de Salamanca.

CORPAS PASTOR, G. (1996): Manual de fraseología española. Madrid: Gredos.

GÓMEZ GONZÁLEZ, A. (2015): Refranes de dar y tomar. Alcalá de Henares: Universidad de Alcalá de Henares.

MELLADO BLANCO, C. (2015): "Parámetros específicos de equivalencia en las unidades fraseológicas (con ejemplos del español y el alemán)". Revista de Filología, 33, pp. 153-174.

PENADÉS MARTíNEZ, I. (1999): La enseñanza de las unidades fraseológicas. Madrid: Arco Libros.

- (2015): La enseñanza de la fraseología vinculada a los contenidos de los manuales de ELE. Fraseología, didáctica y traducción. P. MOGORRÓN HUERTA \& F. NAVARRO DOMÍNGUEZ (eds.). Frankfurt: Peter Lang, pp. 241260.

RUIZ-ZORRILLA CRUZATE, M., H. WALTER \& V. M. MOKIENKO (2012): "Sobre la estructura del nuevo Diccionario paremiológico ruso-español". Paremia, 21, pp. 39-45.

SEVILLA MUÑOZ, J. (1996): "Sobre la paremiología española". Liburukia, 42, 3, pp. 641-672.

- (2001): Reflexiones sobre la elaboración de un refranero multilingüe. Paremia, 10, pp. 121-139. 
- (2004): O concepto "correspondencia" na traduccíon paremiolóxica. Cadernos de fraseoloxia galega, 6, pp. 221-330.

- (2005): Presupuestos paremiológicos de una propuesta metodológica para la enseñanza de los refranes a través de "El Quijote". Paremia, 14, pp. 117-128.

- (2015): "Las TIC en la clase de FLE para la enseñanza de refranes y locuciones". Fraseología, didáctica y traducción. P. MOGORRÓN HUERTA \& F. NAVARRO DOMÍNGUEZ (eds.). Frankfurt: Peter Lang, pp. 261-272.

SARDELLI, M. A. (2010): Los refranes en clase de ELE. Didáctica. Lengua y literatura, 22, pp. 325-350.

TARNOVSKA, O. (2005): "El mínimo paremiológico en la lengua española". La creatividad en el lenguaje: colocaciones idiomáticas y fraseología. A. PAMIES BERTRÁN \& J. D. LUQUE (eds.). Granada: Método, pp.197-217. 